\title{
Perbanyakan Tanaman Pulai Pandak (Rauwolfia serpentina L.) dengan Teknik Kultur Jaringan
}

\author{
Rossa Yunita*), Endang dan Gati Lestarai \\ Balai Besar Penelitian dan Pengembangan Bioteknologi dan Sumberdaya Genetik Pertanian, Bogor 16111 \\ Diterima 14-05-2010Ｄisetujui 10-05-2011
}

\begin{abstract}
Due to over exploitation of its bark for medicinal herbs and made worse by problem in conventional breeding, Rauwolfia serpentina (Pulai pandak), has been considered rare and was currently reported to be an endangered species. Therefore, conservation measure is urgent to be taken. One of them is by in vitro propagation. In this research, in vitro propagation covers several activities, such as (1) shoot induction with the application of MS (Murashige and skoog) media enriched with ZPT 0.0;0.1;0.3 mg/l BAP combined with 0, 1, $2 \mathrm{mg} / 12 \mathrm{ip},(2)$ shoot multiplication by using $0.0 ; 0.5 ; 1.0 \mathrm{mg} / 1 \mathrm{BAP}$ combined with $0.0 ; 0.1 ; 0.2$ and $0.3 \mathrm{mg} / 1$ thidiazuron), (3) root induction IBA at the concentration of $0.0 ; 0.5 ; 1.0 ; 1.5 ; 2.0 ; 2.5 ; 3.0 \mathrm{mg} / \mathrm{l}$, and (4) acclimatization. The result showed that the best shoot induction for calli is the in vitro stem by the application of MS $+0.3 \mathrm{mg} / \mathrm{l} \mathrm{BAP}+1 \mathrm{mg} / \mathrm{l} 2 \mathrm{ip}$ basic media. For shoot multiplication, the best media was MS +0.5 $\mathrm{mg} / 1 \mathrm{BAP}+0.1 \mathrm{mg} / \mathrm{l}$; while the best formula for root induction was $\mathrm{MS}+1 \mathrm{mg} / \mathrm{IBA}$. The best media for plantlet acclimatization is compost + soil mixture in $1: 1$ ratio.
\end{abstract}

Keywords: adventif shoot, in vitro propagation, Rauwolfia serpentina (L.)

\section{PENDAHULUAN}

Rauwolfia serpentina, salah satu anggota pamili Apocynaceae yang merupakan tumbuhan obat potensial untuk dikembangkan, karena disamping dibutuhkan sebagai bahan baku obat tradisional juga digunakan sebagai bahan untuk fitofarmaka. Tumbuhan ini banyak diminati oleh negara-negara industri farmasi dan merupakan spesies tumbuhan yang mempunyai pasaran baik di Amerika Sertikat, Jepang, Jerman, Prancis, Swiss dan Inggris, karena $R$. serpentina mengandung beberapa senyawa diantaranya reserpin, rescinamine dan ajmalin yang digunakan sebagai obat penurun tekanan darah tinggi, tranquilizer (penenang) dan gangguan pada sistem sirkulator. Senyawa-senyawa ini belum dapat dibuat sintetisnya meskipun struktur kimianya telah diketahui (Prasetyorini 2000).

$R$ serpentina merupakan salah satu jenis tanaman yang sudah dinyatakan langka dan sudah terancam punah. Simplisianya diperoleh dengan cara pengumpulan langsung dari alam (hutan) oleh karena permintaan yang cukup tinggi mengakibatkan pemanenan berlebihan, sehingga mengancam kelestariannya (Zuhud et al. 1994 dalam Yahya 2001). Faktor lain penyebab kelangkaan $R$ serpentina adalah bagian yang di manfaatkan sebagai bahan obat adalah akar, tanaman ini sulit di perbanyak secara konvensional dan penyebarannya terbatas. Oleh karena itu perlu segera dilakukan upaya pengembangannya.

*Telp: +6281210486295

Email: rossa_yunita@yahoo.com
Salah satu faktor yang menentukan keberhasilan pengembangan suatu jenis tanaman adalah ketersediaan bibit bermutu. Penyediaan bibit melalui perbanyakan tanaman secara konvensional kurang memadai, seperti yang dilaporkan oleh Sudiarto et al. (1985), perbanyakan $R$ serpentina secara konvensional menunjukkan bahwa pertumbuhan biji dan stek batang kurang dari $15 \%$. Persentase tumbuh yang rendah di sebabkan biji bertempurung keras, sehingga daya kecambah juga sangat rendah. Salah satu teknologi yang biasa digunakan dan memberikan harapan dalam penyediaan bibit dalam jumlah besar dan waktu relatif lebih singkat adalah teknik kultur in vitro. Telah banyak tanaman yang berhasil di perbanyak dengan teknik kultur jaringan ini (in vitro) di antaranya yaitu Tebu (Saccharum officinarum L.) (Behera et al. 2009), Pisang (Lee 2010), dan phalenopsis (Kosir et al. 2004)

Perbanyakan secara in vitro dapat dilakukan melalui tiga cara yaitu pembentukan tunas adventif, proliferasi tunas lateral, dan embriogenesis somatik. Penelitian perbanyakan tanaman $R$ serpentina melalui proliferasi tunas telah dilakukan oleh Lestari dan Mariska (2011), dimana tunas apikal dan internodus yang dikulturkan pada media MS+BAP 0,8mg/l memberikan nilai multiplikasi tunas yang lebih tinggi media terbaik untuk induksi perakaran adalah MS+IBA 0,8 mg/l. Perbanyakan $R$ serpentina melalui embriogenesis somatik juga mampu memperbanyak bibit dalam jumalah yang relatif besar (Singh et al. 2009). 
Akan tetapi dengan cara ini kemungkinan akan terjadi variasi somaklonal sehingga bibit yang dihasilkan tidak sama dengan induknya ( Hutami et al. 2006). Pada penelitian ini dilakukan induksi tunas langsung dari daun atau ruas batang untuk mendapatkan tunas yang banyak akan tetapi tidak mengalami perubahan pada sifat genetiknya sehingga bibit yang di hasilkan sama dengan induknya.

Induksi tunas adventif dari eksplan ruas batang dan daun secara in vitro, sejauh ini belum banyak dilaporkan. Pada penelitian ini telah lakukan induksi dan multiplikasi tunas ruas batang dan daun serta induksi perakarannya. Tujuan dari penelitian ini adalah (1) Untuk mendapatkan jenis eksplan dan formulasi media yang temapat untuk induksi tunas (2) Mendapatkan formulasi media yang tepat untuk multiplikasi tunas (3) Mendapatkan Formulasi media yang tepat untuk induksi perakaran secara in vitro dan (4) mendapatkan media tanam yang tepat untuk aklimatisasi.

\section{BAHANDANMETODE}

Penelitian dilakukan bulan Januari hingga Desember 2009 di laboraturium Biologi Sel dan Jaringan, Balai Besar Penelitian dan Pengembangan Bioteknologi dan Sumberdaya Genetik Pertanian (BB-Biogen), Bogor. Bahan tanaman yang digunakan adalah biakan in vitro $R$ serpentina (L.) koleksi BB-Biogen

Tahapan penelitian ini terdiri atas empat kegiatan yaitu (1) penyedian bahan eksplant (2) regenerasi tunas (3) Multiplikasi tunas (4) Induksi perakaran dan (5) aklimatisasi plantlet

(1) Penyediaan bahan eksplant. Biakan in vitro $R$ serpentina (L.) koleksi BB-biogen, disubkultur pada media dasar MS dengan penambahan ZPT BAP 0,1mg/l untuk penyediaan eksplan. Media dasar yang digunakan adalah MS (Murashige \& Skoog 1962), yang diperkaya dengan vitamin dan dilengkapi dengan sukrosa $3 \%$ (w/v), serta dibuat padat dengan menambahkan agar 0,2\% (phytagel/ Gelrate). Selanjutnya $\mathrm{pH}$ media dibuat 5,8 dengan menambahkan $1 \mathrm{~N} \mathrm{NaOH}$ atau $1 \mathrm{~N} \mathrm{HCl}$ sebelum di autoklaf pada suhu $121^{\circ} \mathrm{C}$ selama 15 menit. Biakan di letakkan pada ruang kultur pada suhu $25 \pm 2^{\circ} \mathrm{C}$ dengan intensitas penyinaran sebesar 1.000-2.000lux selama 16 jam.

Setelah biakan berumur 2 bulan, setinggi $\pm 5 \mathrm{~cm}$ dan menghasilkan daun yang memiliki ukuran yang memadai sebagai eksplan (Gambar 1a), maka biakan siap dijadikan eksplan untuk regenerasi tunas. Bagian tanaman yang digunakan sebagai eksplan untuk regenerasi tunas adalah daun dan batang. Daun dipotong segi empat dengan ukuran $\pm 0,7 \mathrm{~cm} \times 0,7 \mathrm{~cm}$ (Gambar $1 \mathrm{~b}$ ) dan batang yang digunakan ialah internodul panjang $\pm 0,7 \mathrm{~cm}$ dan bagian nodul dibuang (Gambar 1c).

(2) Induksi tunas tunas. Pada kegiatan induksi tunas ini mengunakan eksplan daun dan ruas batang dari hasil kegitan 1. media yang di gunakan adalah media dasar MS yang diperkaya dengan ZPT yaitu BAP pada konsentrasi 0,$0 ; 0,1 ; 0,3, \mathrm{mg} / 1$ dikombinasikan dengan $2 \mathrm{ip}$ pada konsentrasi 0, 1, $2 \mathrm{mg} / \mathrm{l}$. Masing perlakuan terdiri atas 30 ulangan. Peubah yang diamati adalah persentase eksplan membentuk tunas, jumlah dan tinggi tunas yang terbentuk.

(3) Multiplikasi tunas. Tunas yang dihasilkan pada kegiatan 2 dipindahkan ke media multiplikasi. Media untuk multuplikasi adalah media dasar MS yang diperkaya dengan BAP pada tingkatan konsentrasi 0,0;0,5; 1mg/l dan di kombinasikan dengan Thidiazuron pada beberapa konsntrasi yaitu 0,$0 ; 0,1 ; 0,2$ dan 0,3 mg/l. Masing-masing perlakuan terdiri atas 30 ulangan. Peubah yang diamati meliputi jumlah tunas dan penampakan visualnya.

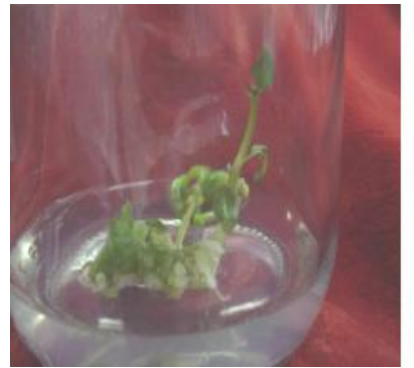

(a)

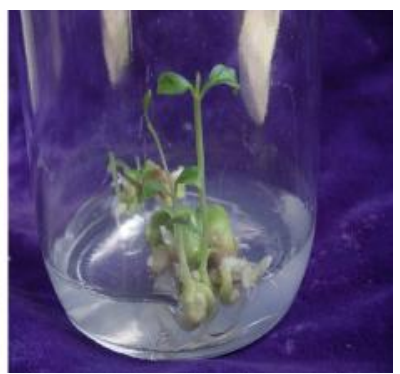

(b)
Gambar 2 (a) Tunas yang terbentuk dari ekplan batang (b) Tunas yang terbentuk dari eksplan daun

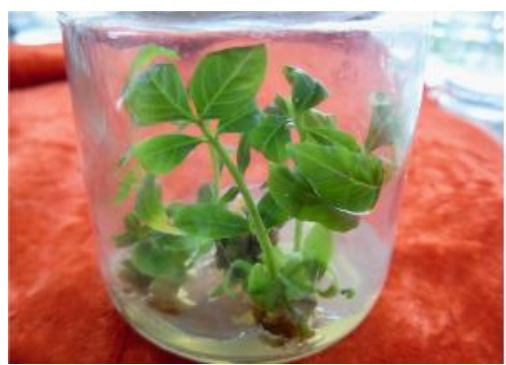

(a)

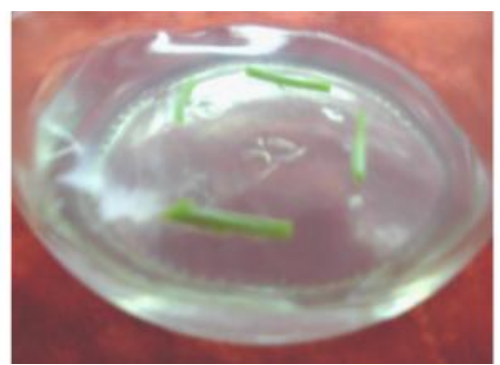

(b)

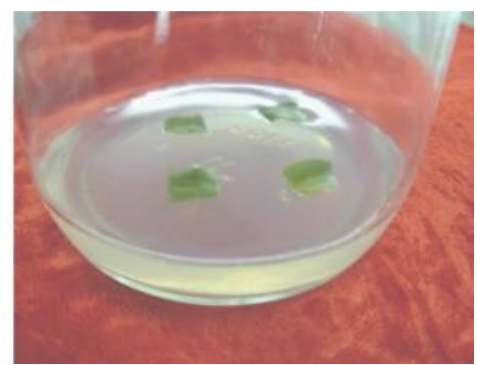

(c)

Gambar 1 (a) biakan $R$ serpentina in vitro yang digunakan sebagai eksplan untuk induksi kalus, (b) batang dan (c) daun 
(4) Induksi perakaran. Tunas yang tingginya $\pm 5 \mathrm{~cm}$, dipindahkan pada media perakaran. Percobaan perakaran menggunakan media MS yang diperkaya dengan auksin IBA pada beberapa tingkatan konsentarasi yaitu 0,$0 ; 0,5$; 1,$0 ; 1,5 ; 2,0 ; 2,5 ; 3,0 \mathrm{mg} / \mathrm{l}$. Masing-masing perlakuan terdiri atas 30 ulangan. Peubah yang diamati adalah jumlah akar dan panjang akar setelah berumur 8 minggu.

(5) Aklimatisasi plantlet. Planlet yang memiliki akar yang telah terbentuk sempurna selanjutnya diaklimatisasi. Aklimatisasi dilakukan dengan cara biakan dikeluarkan dari botol. Biakan selanjutnya ditanam pada media yang telah di siapkan. Media tanam yang digunakan sebagai perlakuan adalah adalah (1) Kompos, (2) tanah, (3) Kompos+pasir (perbandingan 1:1) (4) Tanah+pasir (perbandingan 1:1) (5) Tanah+kompos (6) Tanah+kompos+pasir (perbandingan 1: 1: 1). Masing-masing perlakuan terdiri atas 20 ulangan. Parameter yang diamati adalah persentase tanaman yang hidup setelah diaklimatisasi.

\section{HASIL DAN PEMBAHASAN}

a. Induksi tunas. Hasil percobaan menunjukkan bahwa pada umumnya eksplan yang berasal dari batang mampu membentuk tunas kecuali pada perlakuan $0,1 \mathrm{mg} / 1 \mathrm{BAP}+$ $1 \mathrm{mg} / \mathrm{l}$ 2ip eksplan yang menghasilkan tunas hanya $60 \%$. Untuk eksplan yang berasal dari daun, persentase eksplan yang terbentuk relatif rebih rendah. Bahkan untuk perlakuan $1 \mathrm{mg} / \mathrm{l}$ 2ip, $2 \mathrm{mg} / 1$ 2ip dan 0,1 mg/l BAP+2 mg/1 2iP tidak mampu memacu terbentuknya tunas. Pemberian $0,1 \mathrm{mg} / \mathrm{l}$ BAP dan 0,3 mg/l BA pada eksplan daun mampu menginduksi terbentuknya tunas hingga $80 \%$ sedangkan pada perlakuan $0,3 \mathrm{mg} / \mathrm{l} \mathrm{BAP}+1 \mathrm{mg} / 12 \mathrm{iP}$ dan $0,3 \mathrm{mg} / 1 \mathrm{BAP}$ $+2 \mathrm{mg} / \mathrm{l} 2 \mathrm{iP}$ persentase eksplan daun yang menghasilkan tunas adalah $100 \%$ (Tabel 1).

Jika dilihat pada Tabel 2, penambahan zat pengatur tumbuh (ZPT) 0,1 mg/1 BAP pada media, mampu menginduksi terbentuknya tunas dari ekplan batang ratarata jumlah tunas yang dihasilkan sebanyak 1,4 dan ekplan daun rata-rata jumlah tunas yang dihasilkan sebanyak 1,2. Bila konsentrasi BAP ditingkatkan hingga 0,3 mg/l, maka rataan jumlah tunas yang dihasikan oleh ekplan batang maupun daun juga meningkat yaitu menjadi 1,6 dan 3,6 tunas. Hal yang sama juga terjadi pada tanaman melon (Cucumis melo) peningkatan konsentrasi BAP yang diberikan mampu meningkatkan kemampuan ekplan bertunas (Rohayati 2003). Begitu pula dengan rataan tinggi tanaman, peningkatan konsentrasi BAP yang diberikan hingga $0,3 \mathrm{mg} / \mathrm{l}$ cenderung meningkatkan tinggi tanaman.

Pemberian $1 \mathrm{mg} / \mathrm{l}$ dan 2mg / 2 ip pada eksplan daun mampu menginduksi terbentuknya tunas 1,2 dan 1,4, sedangkan pada eksplan batang tidak mampu menginduksi terbentuknya tunas. 2ip merupakan ZPT yang tergolong kedalam sitokinin yang berperan sebagai promotor dalam pembentukan jaringan

Eksplan daun dan batang yang di tumbuhkan pada media MS yang dikombinasikan dengan $0,3 \mathrm{mg} / \mathrm{l} \mathrm{BAP}$ dari $2 \mathrm{mg} / \mathrm{l}$ 2iP memberikan rataan jumlah tunas yang lebih tinggi dari pada perlakaun lainnya yaitu 2,4 dan 7 (Tabel 2). Biakan yang di kulturkan pada media kombinasi BAP dan 2ip cendrung menghasilkan tunas yang lebih tinggi daripada perlakuan tunggal. Hal ini karena ada sifat sinergis dari kedua jenis sitokin tersebut dalam proses pembelahan dan pembesaran sel.

B. Multiplikasi tunas. Tunas yang terbentuk di subkultur kemedia multiplikasi yaitu media MS+0,1 mg/l BA. Tunas yang disubkultur berukuran $\pm 1 \mathrm{~cm}$ yang mengandung 2 nodus.

Pada Tabel 3, terlihat bahwa pemberian Thidiazuron secara tunggal mampu meningkatkan kemampuan tunas untuk bermultiplikasi. Peningkatan konsentrasi Thidiazuron hingga $0,3 \mathrm{mg} / \mathrm{l}$ mampu meningkatkan jumlah tunas hingga

Tabel 1 Persentase Pembentukan tunas pada formulasi media dan jenis eksplan yang beda pada minggu ke-10 setelah masa tanam

\begin{tabular}{lcc}
\hline \multicolumn{1}{c}{ Perlakuan } & \multicolumn{2}{c}{ Jenis eksplan } \\
\cline { 2 - 3 } Media $(\mathrm{mg} / \mathrm{l})$ & $\%$ ase daun bertunas & $\%$ ase batang bertunas \\
\hline BAP 0,1 & 80 & 100 \\
BAP 0,3 & 80 & 100 \\
2ip 1 & 0 & 100 \\
2ip 2 & 0 & 100 \\
BAP 0,1 + 2iP 1 & 20 & 60 \\
BAP 0,1 + 2iP 2 & 0 & 100 \\
BAP 0,3 + 2iP 1 & 100 & 100 \\
BAP 0,3 + 2iP 2 & 100 & 100 \\
\hline
\end{tabular}

Tabel 2 Pengaruh formulasi media terhadap pertumbuhan biakan minggu ke -8

\begin{tabular}{lccc}
\hline \multicolumn{1}{c}{$\begin{array}{c}\text { Perlakuan media } \\
\mathrm{mg} / \mathrm{l}\end{array}$} & \multicolumn{2}{c}{ Rataan jumlah tunas } & \multicolumn{2}{c}{ Rataan tinggi tunas (cm) } \\
\cline { 2 - 4 } & Batang & Daun & Datang \\
\hline BAP 0,1 & $1,4 \pm 0,19$ & $1,2 \pm 0,21$ & $0,8 \pm 0,16$ \\
BAP 0,3 & $1,6 \pm 0,13$ & $3,6 \pm 0,23$ & $1,4 \pm 0,16$ \\
2ip 1 & $0 \pm 0,0$ & $1,2 \pm 0,23$ & $0,7 \pm 0,08$ \\
2ip 2 & $0 \pm 0,0$ & $1,4 \pm 0,19$ & $0 \pm \pm 0$ \\
BAP 0,1+2iP 1 & $0,4 \pm 0,16$ & $0,6 \pm 0,17$ & 0,14 \\
BAP 0,1+2iP 2 & $0 \pm 0$ & $1 \pm 0,11$ & $0,2 \pm 0,06$ \\
BAP 0,3+2iP 1 & $1,8 \pm 0,18$ & $6 \pm 0,81$ & $0 \pm 0$ \\
BAP 0,3+2iP 2 & $2,4 \pm 0,24$ & $7 \pm 0,94$ & $0,7 \pm 0,16$ \\
\hline
\end{tabular}


4,6 Tunas. Penggunaan BAP secara tunggal pada konsentrasi 0,5 dan $1 \mathrm{mg} / \mathrm{l}$ belum mampu meningkatkan kemampuan tunas bermultiplikasi seperti pada pemberian Thidiazuron secara tunggal. Keadaan yang sama juga terjadi pada taman melinjo (Gnetum gnemon) dimana pemberian Thidiazuron hingga $0,3 \mathrm{mg} / 1 \mathrm{mampu}$ meningkatkan kemampuan tunas untuk bermultiplikasi (Yunita 2004). Hal yang sama juga di temui pada tanaman Plumbago zeylanica L bahwa pemberian Thidiazuron hingga $0,05 \mathrm{mg} / \mathrm{l} \mathrm{mampu}$ meningkatkan kempuan tunas untuk bermultiplikasi. Hal ini karena Thidiazuron memiliki kempuan untuk menginduksi terjadinya proses pembelahan sel (Syahid \& Kristina 2008).

Penggunan BAP dan thidiazuron secara bersamaan mampu menigkatkan kemampuan tunas bermultiplikasi dari pada pemberian BAP atau Thidiazuron secara tunggal. Pada percobaan ini pemberian BAP dan thidiazuron yang optimum adalah pada konsentrasi $0,5 \mathrm{mg} / \mathrm{l}$ BAP dan $0,2 \mathrm{mg} / \mathrm{l}$ Thidiazuron dimana rerata tunas yang dihasilkan adalah 7,7 tunas. Pengunaan thidiazuron pada konsentrasi rendah akan lebih efektif apabila dikombinasi dengan BA, akan tetapi peningkatan konsentrasi BAP dan Thidiazuron cenderung menurunkan kemampuan tunas untuk bermultiplikasi, hal ini juga terjadi pada tanaman Kigelia pinnata dimana kemampuan multiplikasinya meningkat bila diberi Thidiazuron hinga $0,5 \mu \mathrm{M}$ dan bila kosentrasi terus

Tabel 3 Pengaruh formulasi media multiplikasi terhadap rerata jumlah tunas pada umur biakan minggu ke -8

\begin{tabular}{lc}
\hline \multicolumn{1}{c}{ Perlakuan media $(\mathrm{mg} / \mathrm{l})$} & Rerata jumlah tunas \\
\hline BAP 0 Thidiazuron 0,0 & $1,00 \pm 0,00$ \\
BAP 0 Thidiazuron 0,1 & $3,50 \pm 0,50$ \\
BAP 0 Thidiazuron 0,2 & $4,40 \pm 0,48$ \\
BAP 0 Thidiazuron 0,3 & $4,60 \pm 0,48$ \\
BAP 0,5 Thidiazuron 0,0 & $1,10 \pm 0,30$ \\
BAP 0,5 Thidiazuron 0,1 & $4,70 \pm 0,45$ \\
BAP 0,5 Thidiazuron 0,2 & $7,70 \pm 0,45$ \\
BAP 0,5 Thidiazuron 0,3 & $7,50 \pm 0,50$ \\
BAP 1, Thidiazuron 0,0 & $2,70 \pm 0,45$ \\
BAP 1, Thidiazuron 0,1 & $4,80 \pm 0,40$ \\
BAP 1, Thidiazuron 0,2 & $5,10 \pm 0,30$ \\
BAP 1, Thidiazuron 0,3 & $4,90 \pm 0,30$ \\
\hline
\end{tabular}

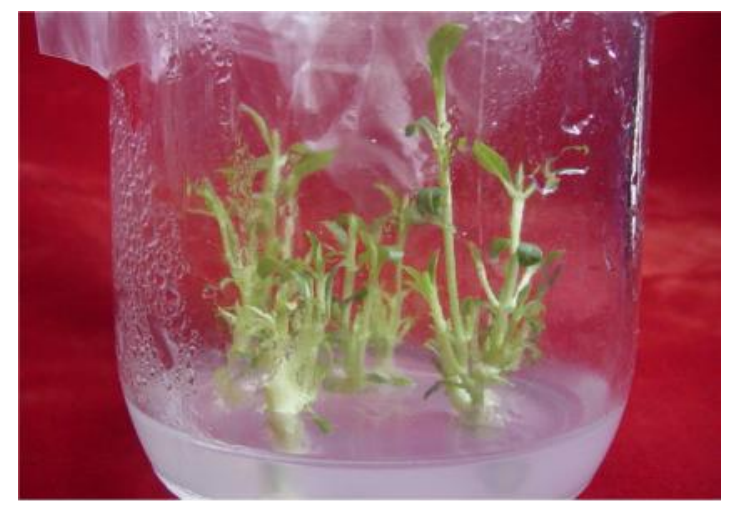

Gambar 3 Tunas yang di multiplikasi pada media MS + 0,5 mg/l BAP $+0,2 \mathrm{mg} / 1$ Thi ditingkatkan maka kemampuan tunas untuk bermultiplikasi menjadi menurun (Thomas \& Puthur 2004).

C. Induksi perakaran. Hasil penelitian menunjukkan bahwa pemberian IBA secara umum mampu menginduksi pembentukan akar pada tunas in vitro. Dari Tabel 4, terlihat bahwa pemberian IBA yang terbaik untuk induksi perakaran adalah pada konsentrasi 1,0 mg/l. Pada konsentrasi tersebut mampu menghasilkan akar lebih banyak dengan nilai rataan 4,8 dan rataan panjang akar 2,6 cm. Peningkatan konsentrasi IBA lebih dari 1mg/l menurunkan kemampun tunas untuk membentuk akar di samping itu akar yang dihasilkan lebih pendek. Menurut Davies (1993), Penambahan auksin pada konsentrasi tertentu pada media biakan mampu menginduksi pembentukan akar, Tetapi bila konsentrasi yang diberikan terlalu tinggi akan menghambat pembentukan akar tersebut. Penambahan auksin eksogen dalam konsentrasi tinggi pada media biakan akan menstimulasi diferensiasi jaringan pembuluh yang cepat, sehingga akan meningkatkan jumlah dan ukuran jaringan tersebut.

IBA merupakan ZPT jenis auksin yang umum digunakan untuk menginduksi perakaran tanaman secara in vitro. Pada tanaman sukun dalam waktu dua bulan eksplan yang ditanam pada WPM+3 mg/l IBA mampu membentuk akar dengan persentase perakaran $60 \%$ dan panjang akar 4,5 cm (Mariska et al. 2004). Pada tanaman Belimbing dewi tunas in vitro yang ditanam pada media $1 / 2 \mathrm{WPM}+3 \mathrm{mg} / \mathrm{l}$ IBA persentase tunas yang berakar $80 \%$ dengan rerata

Tabel 4 Pengaruh konsentrasi IBA terhadap rerata jumlah akar dan rerata panjang akar umur biakan minggu ke -8

\begin{tabular}{ccc}
\hline $\begin{array}{c}\text { Konsentrasi IBA } \\
(\mathrm{mg} / \mathrm{l})\end{array}$ & $\begin{array}{c}\text { Rerata } \\
\text { jumlah akar }\end{array}$ & $\begin{array}{c}\text { Rerata } \\
\text { panjang akar }(\mathrm{cm})\end{array}$ \\
\hline 0,0 & $0,00 \pm 0,00$ & $0,00 \pm 0,00$ \\
0,5 & $1,20 \pm 0,27$ & $1,10 \pm 0,18$ \\
1,0 & $4,80 \pm 0,16$ & $2,60 \pm 0,21$ \\
1,5 & $3,40 \pm 0,16$ & $2,14 \pm 0,01$ \\
2,0 & $2,80 \pm 0,16$ & $1,92 \pm 0,10$ \\
2,5 & $2,80 \pm 0,12$ & $1,70 \pm 0,15$ \\
3,0 & $2,50 \pm 0,20$ & $1,64 \pm 0,10$ \\
\hline
\end{tabular}

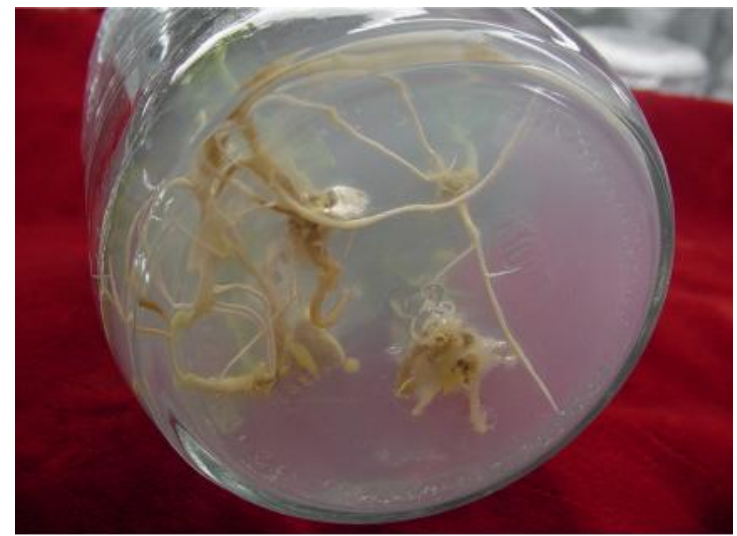

Gambar 4 Akar yang dihasilkan pada media MS + 1 mg/l IBA 
Tabel 5 Persentase tanaman yang hidup setelah berumur 7 minggu setelah aklimatisasi

\begin{tabular}{lc}
\multicolumn{1}{c}{ Jenis media dasar } & Persentase tanaman yang hidup \\
\hline Kompos & 25 \\
Tanah & 25 \\
Kompos + Pasir & 50 \\
Tanah + Pasir & 45 \\
Kompos + Tanah & 80 \\
Kompos + tanah + pasir & 40 \\
\hline
\end{tabular}

jumlah akar 7,0 buah dan rerata panjang akar 4,2 cm (Suryati et al. 2004).

D. Aklimatisasi tunas. Aklimatisasi adalah suatu aktifitas atau kegiatan pemindahan tanaman dari lingkungan yang terkendali (in vitro) ke lingkungan mandiri (eks vitro). Planlet yang pertumbuhannya telah optimal dan memiliki perakaran sempurna dilakuan uji aklimatisasi pada berbagai media tumbuh.

Pada Tabel 5, dapat dilihat bahwa kemampuan planlet untuk tumbuh berkisar dari 25-80\%, kemampuan tumbuh tertinggi yaitu $80 \%$, Pada perlakuan kompos+tanah (perbandingan 1:1). Dengan mengunakan media kompos saja dan tanah saja kemampuan tumbuh tanaman sangat rendah yaitu $25 \%$. Media aklimatisasi yang tepat untuk masingmasing tanaman hasil kultur jaringan berbeda-beda.

Semua planlet yang diaklimatisasi disungkup dengan gelas aqua plastik dengan tujuan untuk menciptakan tingkat kelembaban yang diinginkan. Kelembaban yang tinggi umumnya diperlukan bagi hampir semua tanaman yang berasal dari kultur jaringan karena lapisan kultikula pada daun masih tipis. Stomata belum berfungsi secara normal, serta hubungan jaringan pembuluh akar dan batang belum sempurna.

\section{SIMPULAN}

Dari penelitian yang telah dilakukan dapat disimpulkan bahwa eksplan terbaik untuk induksi kalus adalah ruas batang in vitro yang dikulturkan pada media dasar $\mathrm{MS}+0,3 \mathrm{mg} / \mathrm{l} \mathrm{BAP}+1 \mathrm{mg} / \mathrm{l} 2 \mathrm{iP}$. Formulasi media terbaik untuk multiplikasi tunas adalah $\mathrm{MS}+0,5 \mathrm{mg} / \mathrm{l} \mathrm{BAP}+0,1 \mathrm{mg} / \mathrm{l}$ Thidiazuron. Sedangkan untuk induksi perakaran formulasi media terbaik adalah MS+1 mg/l IBA. Pada tahap aklimatisasi, media tanaman optimum yang di gunakan untuk proses ini adalah campuran Kompos + tanah dengan perbandingan $1: 1$.

\section{UCAPANTERIMAKASIH}

Ucapan terimakasih di sampaikan kepada seluruh peneliti dan teknisi di lingkup Balai Besar Penelitian dan Pengembangan Bioteknologi dan Sumberdaya Genetik Pertanian

\section{DAFTAR PUSTAKA}

Behera, K.K. \& Sahoo, S. 2009. Rapid in vitro micro propagation of sugarcane (Saccharum officinarum L. cv-Nayana) Through Callus Culture, Nature and Science 7(4): 1-10.

Davies, P.J. 1993. The plant hormon: their nature, occrrence and function, In: The plant hormones: physiology, biochemistry and molecular biology, first edition (ed. P. J. davies), kluwer acad. Pub. Pp 1-12.

Hutami, S., Mariska, I. \& Supriati, Y. 2006. Peningkatan keragaman genetik tanaman melalui keragaman somaklonal, Jurnal AgroBiogen 2(2): 81-88.

Kosir, P., Škof, S. \& Luthar, Z. 2004. Direct shoot regeneration from nodes of Phalaenopsis orchids, Acta agriculturae slovenica 83(2): 233-242.

Lee, S.W. 2010. Micropropagation of cavendish banana in taiwan. FFTC Publication . 54 pp

Lestari, E.G. \& Mariska, I. 2011. Perbanyakan dan pentimpanan tanaman Rouvolfia serpentina secara in vitro. Buletin plasma nutfah 7(1): 40-45.

Mariska, I., Suryati, Y. \& Hutami, S. 2004. Mikropropoagation sukun (Artocarpus communis Forst). Kumpulan makalah seminar hasil penelitian BB-biogen. BB-biogen. Bogor. $180-187$.

Murashige, T. \& Skoong, F. 1962. A revised medium for rapih growth and bioassays with tobacco cultures. Physoil.Plant 15: 473-493.

Prasetyorini. 2000. Preservasi Rauvolfia serpentina Benth. Ex. Kurz. (Pulai Pandak) melalui teknik kultur in vitro. Disertasi. IPB. Bogor. 105 hal

Rohayati. 2003. Aplikasi organogenesis dan embriogenesis untuk perbanyakan bibit melon (Cucumis melo L.) cv. Japanese. Prosiding Seminar Teknologi untuk Negeri 2003.

Sudiarto, A., Rusli, S., Chairani, F., Moko, H. \& Januwati, N.M. 1985. Tiga puluh tahun penelitian tanaman obat: Seri pengembangan 5. Departermen Penelitian dan Pengembangan Pertanian, Bogor.

Supriyati, Y., IMariska, I., Husni, A. \& Hutami, S. 2004. Inisiasi dan Perkembangan perkaran serta aklimatisasi belimbing dewi (Averrhoa carambola L). Kumpulan Makalah Seminar Hasil Penelitian BB-Biogen. BB-Biogen. Bogor. 189-193.

Singh, P. Singh, A., Shukla, A., Singh, L., Pande, V. \& Nailwal, T. 2009. Somatic embryogenesis and in vitro regeneration of an endangered medicinal plant sarpgandha (Rauvolfia serpentina. L). J.Exp Biol 6(3): 74-79

Syahid, S.F. \& Kristina, N.N. 2008. Multiplikasi tunas, aklimatisasi dan analisis mutu simplisia daun encok (Plumbago zeylanica L.) asal kultur in vitro periode panjang. Bul. Littro. XIX(2): $117-128$

Thomas, T.D. \& Puthu, J.T. 2004. Thidiazuron induced high frequency shoot organogenesis in callus from Kigelia pinnata L. Bot.Bull. Acad.Sin 45: 307-313.

Yahya, A. \& Fadly. 2001. Pertumbuhan, Biomassa dan Kandungan Alkaloid Akar Pule Pandak (Rauwolfia serpentina Benth.) Hasil Kultur In vitro. http://repository.ipb.ac.id

Yunita, R. 2004. Multiplikasi tunas melinjo (Gnetum gnemon) secara in vitro. Jurnal Sagu 3(1): 1-8. 